\title{
Adsorption of Charged Surfactants onto Calcium Carbonate
}

S. F. Hassan, ${ }^{1}$ S. Kamireddy, ${ }^{1}$ M. P. Yutkin, ${ }^{1}$ C. J. Radke, ${ }^{2}$ T. W. Patzek $^{1}$

${ }^{1}$ King Abdullah University of Science and Technology, Thuwal, KSA ${ }^{2}$ University of California, Berkeley, USA

Summary

The fundamental study of adsorption in this manuscript pertains to a wellknown process of low salinity water flooding (LSW), which is a potentially economic way of incrementing productivity of oil reservoirs. Our preliminary results indicate adsorption of a positively charged surfactant CTAB (cetrimonium bromide) regardless of brine type and charge at the surface. We show that the surfactant behavior mimics that found at charged crude oil-brine interfaces. This result partially explains strong crude oil interaction with calcium carbonate and adds to the difficulties associated with oil extraction by LSW.

\section{Introduction}

Incremental oil recovery by lowered salinity water flood (LSW) or tuned composition waterflood has lately received great attention owing to its favorable economics, environmental benignness, and simplicity at large scale (Morrow and Buckley, 2011). The potential of the process has been demonstrated for sandstones and carbonates (Yousef et al., 2011; Tang and Morrow, 1997).

Carbonate reservoirs (limestone, dolomite, chalk) are of a special interest for LSW process since they contain more than $60 \%$ of the world's recoverable oil (Bai and $\mathrm{Xu}, 2014$ ). However, despite a few decades of research, no commercial process exists. This is due to complexity of the process that encompasses a wide range of disciplines starting from surface science, chemistry, physics, and down to coupled transport phenomena in fractures and capillaries.

All natural minerals are high energy surfaces and, therefore, hydrophilic. Aliphatic oils fundamentally cannot out compete water or brine when interacting with such surfaces. That is, aliphatic oils never adhere chemically to mineral surfaces. Crude oils, in contrast, contain chemically active components that can strongly interact with minerals and change their wettability (make them more oil wet) reversibly or irreversibly. Those that invoke irreversible change (i.e., asphaltenes) are of special interest.

Lager et al. (2006) proposed a realistic mechanism of crude-oil deposition and wettability change involving carboxylate groups (Yutkin et al., 2016). The carboxylate would form from carboxylic at crude oil brine interface at high $\mathrm{pH}$. This multicomponent ion-exchange mechanism was widely accepted in the literature, used, and discussed by several groups (Hu et al., 2019; Eftekhari et al., 2017; Srisuriyachai and Meekangwal, 2017; Yutkin et al., 2016; Lager et al., 2011). Yet, recent direct confirmation for silica does 
not provide strong evidence (Hu et al., 2019). No direct evidence has been presented for calcium carbonate so far. In this work we investigate adsorption of various charged aqueous surfactants onto calcium carbonate. The chosen functional groups are present in crude oils and are charged at typical reservoir $\mathrm{pH}$. Our findings support the fact calcium carbonate surface is neutral and ions compete for adsorption in $\beta$-plane. For example, we found that amine-based surfactants strongly interact with calcium carbonate surface regardless of the used brine. It implies that crude oil can interact with calcium carbonate surface independently of brine composition.

Methods and Materials

Chemicals

For comparative bulk adsorption studies we used fused amorphous silica powder for chromatography, 325 mesh with surface area of $\sim 5 \mathrm{~m}^{2} / \mathrm{g}$ and $99.5 \%$ purity, which was obtained from (Alfa Aesar, USA). For zeta potential measurements, we used calcite $5 \mu \mathrm{m}$ powder with $99.5 \%$ purity (metal base) obtained from Alfa, Aesar, USA. For bulk adsorption measurements we used synthetic calcium carbonate nanopowder $<100 \mathrm{~nm}$ with $>99.9 \%$ purity obtained from (NanoShel LLC, Willmington, USA).

Cetyltrimethylammonium chloride (CTAC) as $25 \%$ wt in water was obtained from (Sigma-Aldrich, USA). Cetyltrimethyl ammonium bromide (CTAB) high purity powder was obtained from (VWR Life Science, USA). Calcium chloride dihydrate powder with purity $99.5 \%$ was obtained from (Sigma-Aldrich, USA). Sodium carbonate decahydrate powder was obtained from (Sigma-Aldrich, USA). Sodium hexanoate powder was obtained from (Sigma-Aldrich, USA). Sodium dodecyl sulfate powder was obtained from (Sigma-Aldrich, USA). Sodium chloride powder was obtained from (Fisher Scientific, USA). Deionized water (DI water) was obtained from Milli-Q water purification system, which delivers ultrapure type 1 water with $18.2 \mathrm{M} \Omega \cdot \mathrm{cm}$ at $25{ }^{\circ} \mathrm{C}$ and TOC below 5 ppb (Merck Millipore Corporation, USA).

QCM-D Procedures

A QCM-D Omega (Biolin Scientific) was used in this work to measure adsorption of charged surfactants onto silica and calcium carbonate surfaces. Quartz resonators coated with silica (Biolin Scientific, QSX 303) or calcium carbonate (Biolin Scientific, QSX 999) were used for silica and calcium carbonate surfaces, respectively. To ensure reproducibility, all resonators were used only once.

New silica sensors undergo the following washing procedure prior to experiment. First, the sensors were sonicated in deionized water (DI water) for 10 min followed by G6 nitrogen purging. Dried sensors were plasma treated using Pico low-pressure plasma system with $13.56 \mathrm{MHz}$ generator frequency and a maximum power of $200 \mathrm{~W}$ (Diener electronic, Germany). Sensors were loaded in the cleaner and vacuumed to 0.3 mbar pressure 
followed by ignition of the plasma under continuous oxygen injection at 5 sccm for 10 min. Only $15 \%$ of power was applied.

Due to solubility of the calcium carbonate coating, QSX 999 sensors required a different cleaning procedure, which consisted of G6 nitrogen purging followed by plasma cleaning.

After plasma cleaning, sensors were transferred to the QCM-D chamber for experiments. Temperature was controlled and set at the laboratory air temperature of $21 \circ \mathrm{C}$. All experiments were run at $50 \mu \mathrm{L} / \mathrm{min}$ flow rate, unless specified otherwise. Typical duration of experiment was about 100 min. Resonant frequencies and dissipation of first to thirteenth overtones were collected. Baseline stability criteria were a frequency drift less than 0.1 $\mathrm{Hz} /$ min for at least 3 overtones and dissipation drift less than $10^{-7} / \mathrm{min}$ for at least 3 overtones for a minimum of 2 min. Having obtained a stable baseline, the reference solution was flushed for an extra 10-20 min. Then solution containing a surfactant was injected for 20- 40 min followed by re-injection of baseline solution. Each experiment was reproduced at least 2 times. The obtained frequency data were analyzed and plotted in MATLAB (MATLAB R2016a, MathWorks). Data are filtered using a $2^{\text {nd }}$ order low pass filter with a cutoff frequency of $0.05 \mathrm{~Hz}$ by the Butterworth built-in MATLAB function.

Prior to experiments with calcium carbonate sensors, all brines were preequilibrated with $5 \mu \mathrm{m}$ calcite powder at a fixed air partial pressure of $\mathrm{CO}_{2}(\sim$ $350 \mathrm{ppm}$ ). This includes equilibration of solutions with surfactant. We used small amount of calcite for equilibration to avoid modification of the surfactant concentration due to adsorption on calcite.

QCM-D Interpretation

Increasing the mass of the oscillating crystal by solute adsorption lowers the oscillation frequency and leads to the classical Sauerbrey relation (Sauerbrey, 1959)

$$
\hat{\Gamma}=-C \frac{\left(f-f^{*}\right)}{n}=-C \frac{\Delta f}{n}
$$

where $\hat{\Gamma}$ is solute adsorbed mass density (mass/area), commonly written as $\Delta m$ (Rodahl and Kasemo, 1995), $f^{*}$ is the bare-crystal frequency $(5 \mathrm{MHz}), f$ is the measured frequency with adsorbed mass, $n$ is the overtone number ( 1 , 3,5 etc.), and $C=17.7 \mathrm{ng} /\left[\mathrm{cm}^{2} \cdot \mathrm{Hz}\right]$ (for $5 \mathrm{MHz}$ AT-cut quartz crystal) is an apparatus constant. Therefore, adsorbed areal mass is directly available from QCMD with no prior calibration.

Solute molecules adsorb to the substrate crystal from an overlying Newtonian liquid solution of bulk density $\rho$ and viscosity $\eta$. The characteristic distance over which the liquid oscillates is $\delta=\sqrt{2 \eta / \rho \omega}$, where $\omega$ is crystal angular frequency (Kanazawa and Gordon, 1985). 
When liquid-soluble species adsorb, crystal oscillation also oscillates the covering liquid altering both frequency and dissipation. Eq. 1 is no longer valid and must be modified. Simplification of Eq. 24 from Voinova et al. (1999) yields

$$
\frac{\Delta f_{n}}{n}=-\frac{1}{C} \hat{\Gamma}-\frac{\beta}{n^{1 / 2}} \sqrt{\rho \eta}
$$

where the factor $\beta \equiv \sqrt{f^{*} / \pi} / 2 h_{q} \rho_{q}$. is a second instrument constant; $h_{q}$ is the thickness of the quartz crystal and $\rho_{q}$ is its mass density. The first term on the right of Eq. 2 is Eq. 1. Adsorption reduces the frequency of the vibrating crystal. This term is independent of the particular overtone number. The second term is the so called "density-viscosity" effect. It corrects for oscillation of the overlying liquid solution and scales inversely with the square root of overtone number. For non-adsorbing liquid solutions, QCM-D frequency (and dissipation) shifts provide a sensitive means to measure solution viscosity.

Following Eq. 25 from Voinova et al. (1999) we obtain simplified expression for dissipation

$$
\Delta D_{n}=\frac{2 \beta}{n^{1 / 2} f^{*}} \sqrt{\rho \eta}
$$

Dissipation is dimensionless and positive relative to the crystal oscillating in air. There is no dissipation contribution from a purely elastic adsorbed layer. Thus, this provides a convenient means to account for the "density-viscosity" effect.

In our experiments, frequency and dissipation shifts are measured relative to a baseline composition, typically salt solutions devoid of adsorbing solute, or $\Delta f_{n}=f-f_{o}$ and $\Delta D_{n}=D-D_{o}$. Hence, the viscosity-density terms in Eqs. 2 and 3 , respectively, change to

$$
\frac{\Delta f_{n}}{n}=-\frac{1}{C} \hat{\Gamma}-\frac{\beta}{n^{1 / 2}}\left(\sqrt{\rho \eta}-\sqrt{\rho_{o} \eta_{o}}\right)
$$

and

$$
\Delta D_{n}=\frac{2 \beta}{n^{1 / 2} f^{*}}\left(\sqrt{\rho \eta}-\sqrt{\rho_{o} \eta_{o}}\right)
$$


where the $o$ subscript indicates a baseline solution. Correction for "densityviscosity" effect of the liquid-solution overlayer is available in QCM without separate measurements of solution density and viscosity. From Eqs. 4 and 5

$$
\frac{\Delta f_{n}}{n}=-\frac{1}{C} \hat{\Gamma}-\frac{\Delta D_{n} f^{*}}{2}
$$

Thus, dissipation measurement provides a means to correct for the "densityviscosity" effect.

AFM Procedures

AFM was used to evaluate surface morphology of sensors through the zsensor channel (topography channel). Images were obtained using Bruker Dimension Icon Model (Bruker Corporation, Massachusetts, CA, USA) under air tapping mood with a RTESPA tip (MPP-11120, $\mathrm{k}=20-80 \mathrm{~N} / \mathrm{m}$ ). The scan rate was $0.996 \mathrm{~Hz}$ with a resolution of 512 samples per line. A sample point was selected around the center of sensor to be scanned at multiple levels $\left(10 \times 10,1 \times 1\right.$, and $\left.0.25 \times 0.25 \mu \mathrm{m}^{2}\right)$. Gwyddion software was used to process, visualize and analyze all data (Necas and Klapetek, 2012). Roughness is reported over the scanned area as arithmetical mean ( $\mathrm{Ra}$ ) and root mean square $(\mathrm{Rq})$. Two runs were made on QCM-D sensors: clean new sensors and sensors after experiment.

Total Organic Carbon

Total organic carbon uses the catalytic combustion-oxidation method and the chemiluminescence detection to find total carbon (TC), inorganic (IC) and hence the total organic carbon (TOC) in samples. The apparatus used here was a Shimadzu TOC-L Shimadzu (Kyoto, Japan), which heats samples to 680 -C with a platinum catalyst in an oxygen-rich environment.

\section{PALS Zetasizer}

All measurements reported were done at a temperature of $20 \circ \mathrm{C}$ on Zetasizer Nano ZS (Malvern Instruments Ltd, Malvern, UK) fitted with a disposable folded capillary cell (DTS1070). For all measurements, AC voltage of $40 \mathrm{~V}$ was applied across an electrode spacing of $16 \mathrm{~mm}$. Five repeat measurements on each sample were done to check repeatability, typical error is within $\pm 5 \mathrm{mV}$. All measured electrophoretic mobilities were converted into zeta potential using Smoluchowski's formula (Hunter, 1981).

Low ionic strength suspensions (10 mM of ionic strength) were measured at slow field mode, as the sample conductivity is low enough to measure mobilities over a wider voltage range that is used to determine the zetapotential distribution. High ionic-strength suspensions (100 mM of ionic strength) were measured at fast electric field mode (monomodel), at which sharp responses to the applied voltage are clearly visible.

Results and Discussion 


\section{Calcium Carbonate Surface Charge and Zeta Potential}

Aqueous calcium-carbonate surface chemistry differs from that of silica and other minerals because of high reactivity of calcium carbonate. Both positive and negative charges exist on its surface, contrary to silica. Looking from crystallography point of view, calcite surface is essentially neutral because of the same number of positive and negative charges. Bulk aqueous ions can specifically interact with calcium carbonate surface binding sites and bring in charge. Therefore, charge arises in the $\beta$-plane due to ions bound via specific interactions (Yutkin et al., 2016). The diffuse layer starts at the $d$-plane to neutralize charge in the $\beta$-plane caused by specific interactions and/or excess of charge in the $\beta$-plane caused by neutralization of some sites at the surface (Yutkin et al., 2016, Fig. 4). For instance, positive zeta potential implies excess of negative charge in diffuse layer and positive charge in the $\beta$-plane. In this framework it is incorrect to speak about calcium carbonate surface charge, the surface is neutral, all the charge accumulates in the $\beta$ plane. A corollary from the above model is that any ion that interacts specifically with the surface is a potential determining ion (PDI).

The most convenient way of inferring surface charge is zeta-potential measurement. There are two techniques for such measurement: phase analysis light scattering (PALS or Laser Doppler Electrophoresis) and streaming potential (SP). Both have advantages and limitations. In our work we used PALS method, which contrary to SP, permits a wider ionic strength working range and relatively simple operation. Yet this method suffers from laser scattering issue.

We measured zeta potential of calcium carbonate in three different brines containing $\mathrm{Na}_{2} \mathrm{CO}_{3}, \mathrm{CaCl}_{2}$, or $\mathrm{NaCl}$. Our results for $\mathrm{Na}_{2} \mathrm{CO}_{3}$ brine compare well with previous findings where authors carefully equilibrated the brines (see Fig. 1 below, Song et al. (2017, Fig. 3), and Heberling et al. (2011, Fig. 6)). However, calcium carbonate zeta potential in $\mathrm{CaCl}_{2}$ and $\mathrm{NaCl}$ deviate yielding neutral and negative charge in the $\beta$-plane respectively. We attribute such deviation to laser scattering. In this work, we report zeta potential values at infinite dilution, which eliminates problems caused by laser scattering (see Fig. 1). 


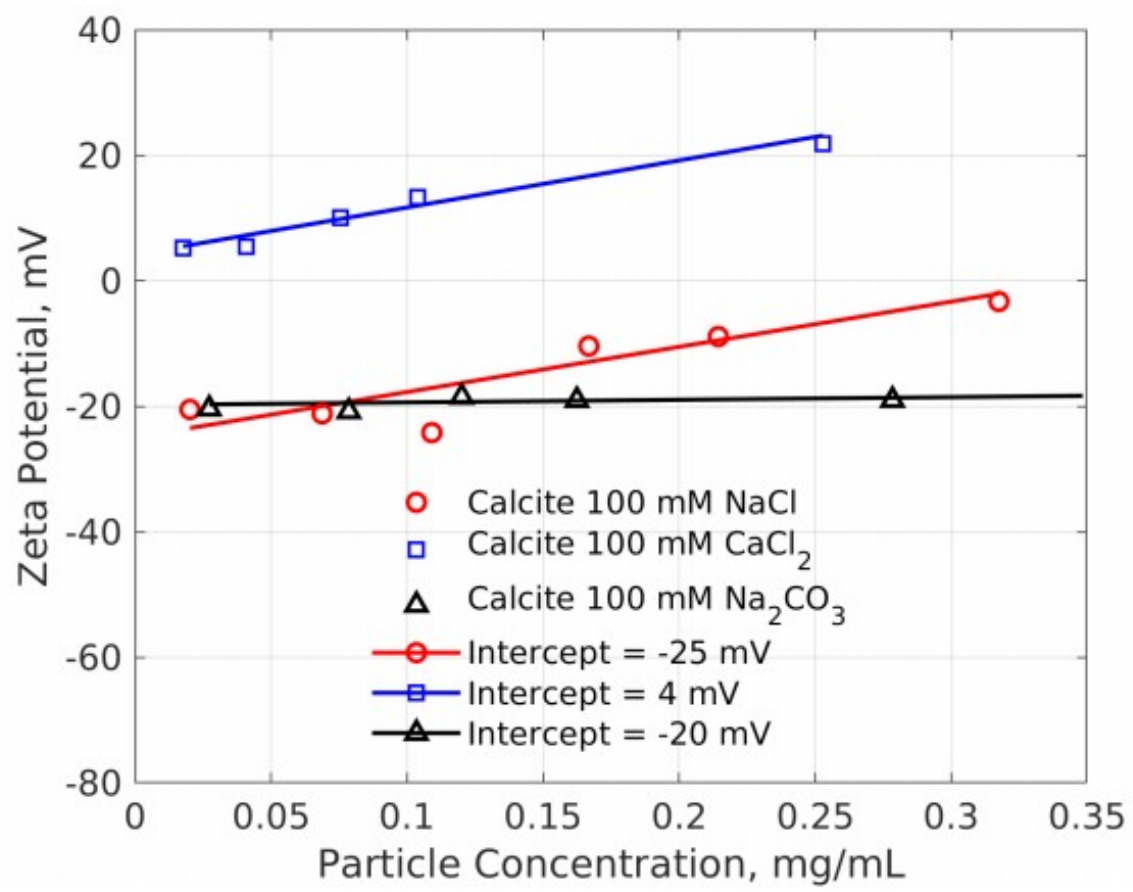

Figure 1 Variation of calcium carbonate zeta potential depending on particle concentration in suspension used for PALS measurement (open symbols). Linear regression (straight lines) intercepts of $25 \mathrm{mV}$, $4 \mathrm{mV}$, and $-20 \mathrm{mV}$ correspond to zeta potential at infinite dilution in $100 \mathrm{mM} \mathrm{NaCl}, \mathrm{CaCl}_{2}$, and $\mathrm{Na}_{2} \mathrm{CO}_{3}$ brines respectively.

\section{Adsorption}

Choice of functional groups for adsorption study should be justified by their presence in crude oil and their charge in solution at typical reservoir conditions. For example, it is widely accepted that carboxylic groups are present in crude oil. Additionally, they are active, i. e. are present in charged form (carboxylate), at typical reservoir $\mathrm{pH}$ (we assume here $\mathrm{pH}$ of 6 and above). Some researchers proposed that amines, aromatic amines, or $\mathrm{R}-\mathrm{COOCa}^{+}$groups exist at crude oil brine interface in significant amounts (Hu et al., 2019; Eftekhari et al., 2017; Brady and Thyne, 2016).

Table 1 A qualitative summary of calcium carbonate zeta potential in three equilibrated brines $\mathrm{NaCl}$, $\mathrm{CaCl}_{2}$, and $\mathrm{Na}_{2} \mathrm{CO}_{3}$.

\begin{tabular}{llll}
\hline Solution $^{a}$ & $\mathrm{pH}$ measured & $\mathrm{pH}$ calculated $^{b}$ & Zeta potential, $\mathrm{mV}$ \\
$\mathrm{Na}_{2} \mathrm{CO}_{3}, 100 \mathrm{mM}$ & 10 & 9.9 & Negative \\
$\mathrm{NaCl}, 150 \mathrm{mM}$ & 8.3 & 8.4 & Negative \\
$\mathrm{CaCl}_{2}, 100 \mathrm{mM}$ & 7.2 & 7.4 & Positive
\end{tabular}

\footnotetext{
${ }^{a}$ All solutions were equilibrated at atmospheric $\mathrm{CO}_{2}$ partial pressure, around $300 \mathrm{ppm}$

${ }^{b}$ Calculations were performed by PHREEQC, see Appendix C
}

We estimated the percentage of active (charged) form of the three functional groups (carboxylic, ternaty amine, and aromatic amine) depending on reservoir $\mathrm{pH} .{ }^{a}$ For this estimation we assumed that: 1 ) a carbonate reservoir 
is an infinite buffer that imposes its equilibrium $\mathrm{pH}$ (which depends on amount of $\mathrm{CO}_{2}$ available to the reservoir) onto whatever brine is injected into it. That is if low salinity brine of pH 6 was injected, the reservoir would change it to an equilibrium $\mathrm{pH}$, which depends on the reservoir properties; 2 ) acidity constants for acid form of the aforementioned functional groups being the same as for acetic acid $\left(\mathrm{CH}_{3} \mathrm{COOH}\right.$, pKa $\left.=4.75\right)$, protonated ammonia $\left(\mathrm{NH}_{4}^{+i i}, \mathrm{pKa}=9.25\right)$, and protonated pyridine $\left(\mathrm{PyH}^{+}, \mathrm{pKa}=5.25\right)$, respectively. Aliphatic groups or side chains change the constant values only slightly, and their effect was neglected.

Fig. 2 shows percentage of functional groups in charged form depending on imposed $\mathrm{pH}$. pKa values are easily identifiable in the figure at $50 \%$ conversion. More importantly, the figure demonstrates that aromatic amines exist in non-charged state in $\mathrm{pH}$ range above 6 ; amines should be considered in reservoirs with $\mathrm{pH}$ below 9.25, while carboxylates are active in a wide range from $\mathrm{pH} 4.75$ onward. PHREEQC input file of the above calculation is available in Appendix C (Parkhurst and Appelo, 2013).

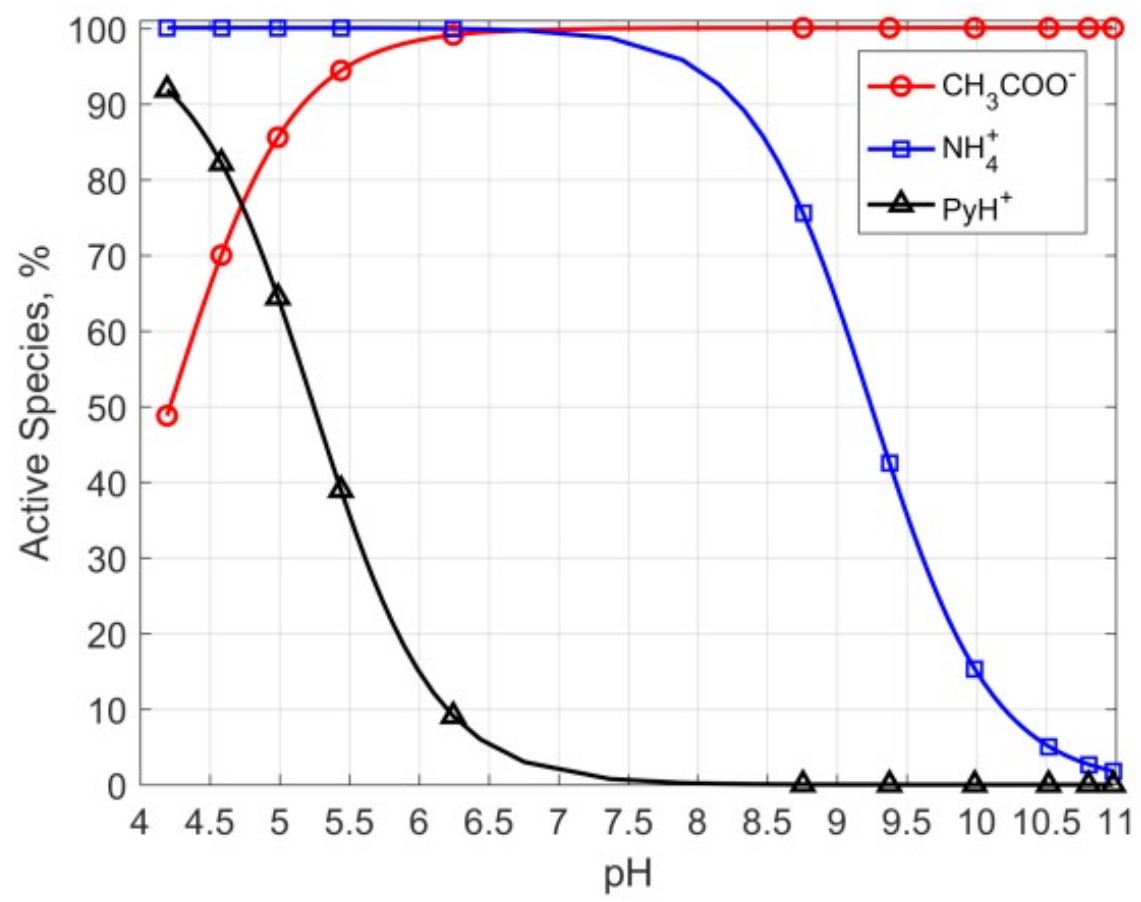

Figure 2 An estimation of $p H$ dependent percentage of charged form of $R-C O O H(p K a=4.75)$, $R^{2}-N R_{3}^{1+}(p K a=9.25)$, and $R-P y H^{+}(p K a=5.25)$ based on acidity constants of acetic acid, protonated ammonia, and protonated pyridine, respectively.

Therefore, we exclude pyridine from further consideration leaving negatively charged carboxylate and positively charged ammonium salts. In addition to carboxylate, we also studied adsorption of sulfate group via sodium dodecyl sulfate. We used sodium hexanoate (NaHex) for carboxylate adsorption, cetrimonium bromide/chloride (CTAB/CTAC) as ammonium salt (quaternary 
ammonium salt charge does not depend on $\mathrm{pH}$, which makes it easier to work with), and sodium dodecyl sulfate (NaDS or SDS) for sulfate group. Adsorption with Excess of Negative Charge at Calcium Carbonate Surface Bulk adsorption studies on powdered calcium carbonate are challenging because of insufficient surface area (see Appendix A). This problem is typically addressed by fine grinding of the material. However, fine particles often agglomerate in solution rendering such approach useless. Besides, calcite grinding can lead to surface property change due to amorphisation or formation of metastable phases that are not desired. Stabilizing agents can be introduced to prevent agglomeration. However, such agents interfere with the surface chemistry. We attempted to study bulk adsorption on crystallized nano calcium carbonate with supposedly larger surface area (see Appendix A). The results were ambiguous because of the aforementioned agglomeration tendency.

We utilized quartz crystal microbalance with dissipation monitoring (QCM-D) for adsorption study. First, we validated the method by studying adsorption of $\mathrm{CTAB}_{\mathrm{C}} \mathrm{CTAC}^{b}$ onto silica, which is a well studied system (see Appendix B).

Sodium carbonate creates excess of negative charge in the $\beta$-plane of calcium carbonate (Table 1 and Song et al. (2017, Fig. 3)). So, we studied CTAC adsorption in equilibrated brine containing $100 \mathrm{mM}$ of $\mathrm{Na}_{2} \mathrm{CO}_{3}$. Fig. 3 shows QCM-D response upon injection of $1 \mathrm{mM}$ solution of CTAC in calciteequilibrated $100 \mathrm{mM} \mathrm{Na}_{2} \mathrm{CO}_{3}$. For the first $15 \mathrm{~min}$ a stable baseline is established. At $15 \mathrm{~min}$, a $1 \mathrm{mM}$ CTAC solution in $100 \mathrm{mM}$ of $\mathrm{Na}_{2} \mathrm{CO}_{3}$ is injected. The abrupt change in frequency suggests strong and fast adsorption of CTAC onto calcium carbonate. At about $40 \mathrm{~min}$, baseline solution is flushed causing stepwise desorption. According to Eq. 6 the corrected frequency drop is $-14 \mathrm{~Hz}$, which corresponds to $249 \mathrm{ng} / \mathrm{cm}^{2}$ of adsorbed areal mass (see Eq. 1). This is very close to the silica result (see Appendix B) and corresponds to formation of bilayer. Desorption of CTAC is also stepwise by analogy to silica. 


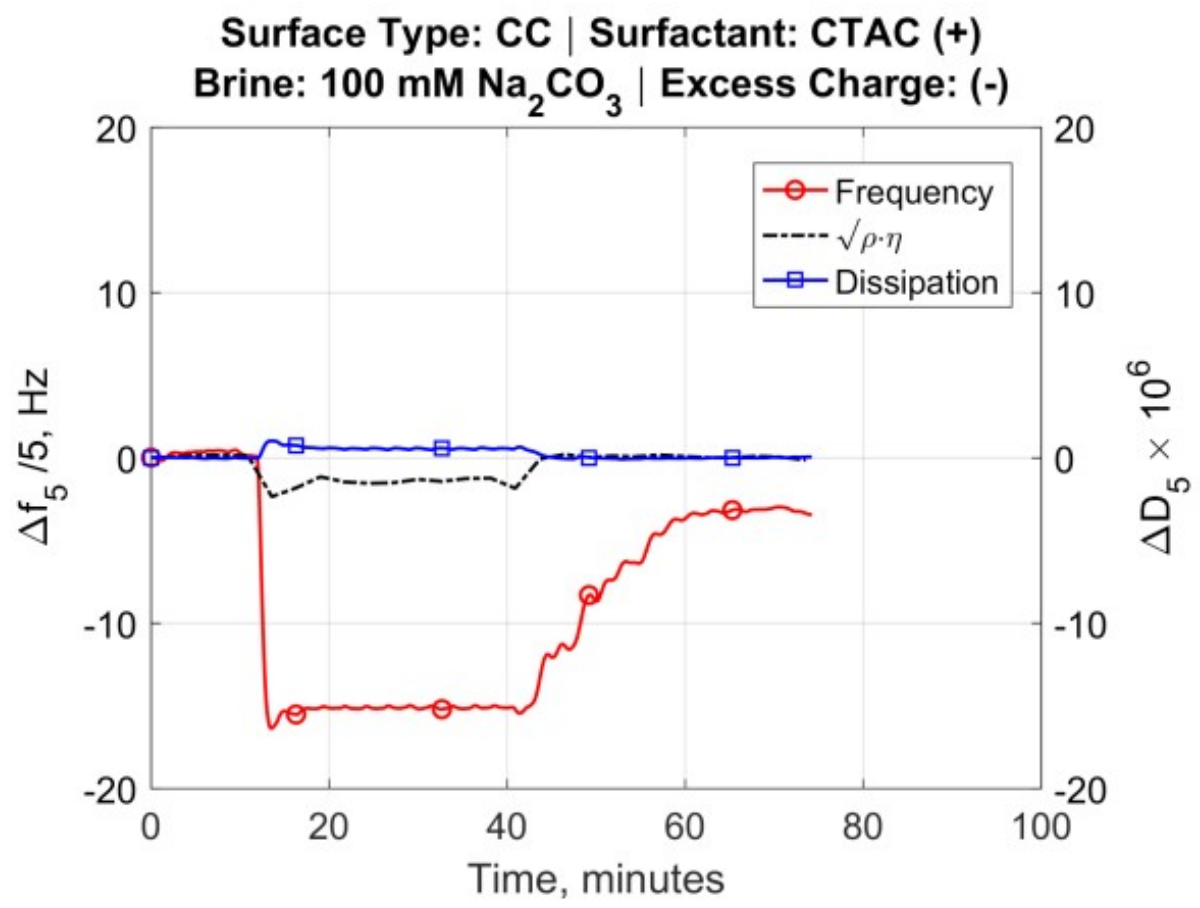

Figure 3 Adsorption of CTAC measured by flow through QCM-D experiment on calcium carbonate. The response at $15 \mathrm{~min}$ is from injection of $1 \mathrm{mM}$ CTAC in $100 \mathrm{mM}$ equilibrated $\mathrm{Na}_{2} \mathrm{CO}_{3}$. The PHREEQC calculated equilibrium pH at atmospheric $\mathrm{CO}_{2}$ is 9.9, observed 10.2. Note the small "density-viscosity" effect denoted by dash-dotted line. Corrected response for adsorption is around $-14 \mathrm{~Hz}$.

Knowing calcium carbonate surface area and CTAC cross-sectional area, we estimate how many surface sites were active. QCM-D surface area is 0.785 $\mathrm{cm}^{2}$ as reported by the QCM-D supplier. We estimated CTAC cross-sectional area to be $36 \AA^{2}$ (see Appendix B and Velegol et al. (2000, Fig. 2)). Simple calculation gives 2.2 sites $/ \mathrm{cm}^{2}$, which is close to the frequently used value of for surface complexation modeling (Eftekhari et al., 2017; Hiorth et al., 2010). Assuming calcite surface site density of 5 sites $/ \mathrm{nm}^{2}\left(5 \cdot 10^{14}\right.$ sites $/ \mathrm{cm}^{2}$ ), we see that less than a half of the available surface sites were active, which is a reasonable number given considerable size of CTAC.

For consistency we also explored adsorption of NaHex and NaDS on negatively charged calcium carbonate surface. Fig. 4 shows QCM-D response upon injection of $50 \mathrm{mM}$ of NaHex in $100 \mathrm{mM}$ of equilibrated $\mathrm{Na}_{2} \mathrm{CO}_{3}$. For the first $20 \mathrm{~min}$ a stable baseline is established. At about $20 \mathrm{~min}, 50 \mathrm{mM}$ NaHex solution in $100 \mathrm{mM}$ of $\mathrm{Na}_{2} \mathrm{CO}_{3}$ is injected. At about $50 \mathrm{~min}$, baseline solution is flushed. Although there is a notable frequency shift, hardly anything adsorbed. According to Eq. 6 the frequency shift is fully explained by densityviscosity variation between baseline and the injected solution (see dotdashed line). So notable density viscosity variation is caused by much higher $\mathrm{NaHex}$ concentration in the injected brine compared to the CTAC experiments. No adsorption of NaHex is observed even at high concentration. Likewise, no adsorption is recorded for NaDS (see Fig. 5). 
These results correlate with our previous findings for the negatively charged silica surface (Hu et al., 2019).

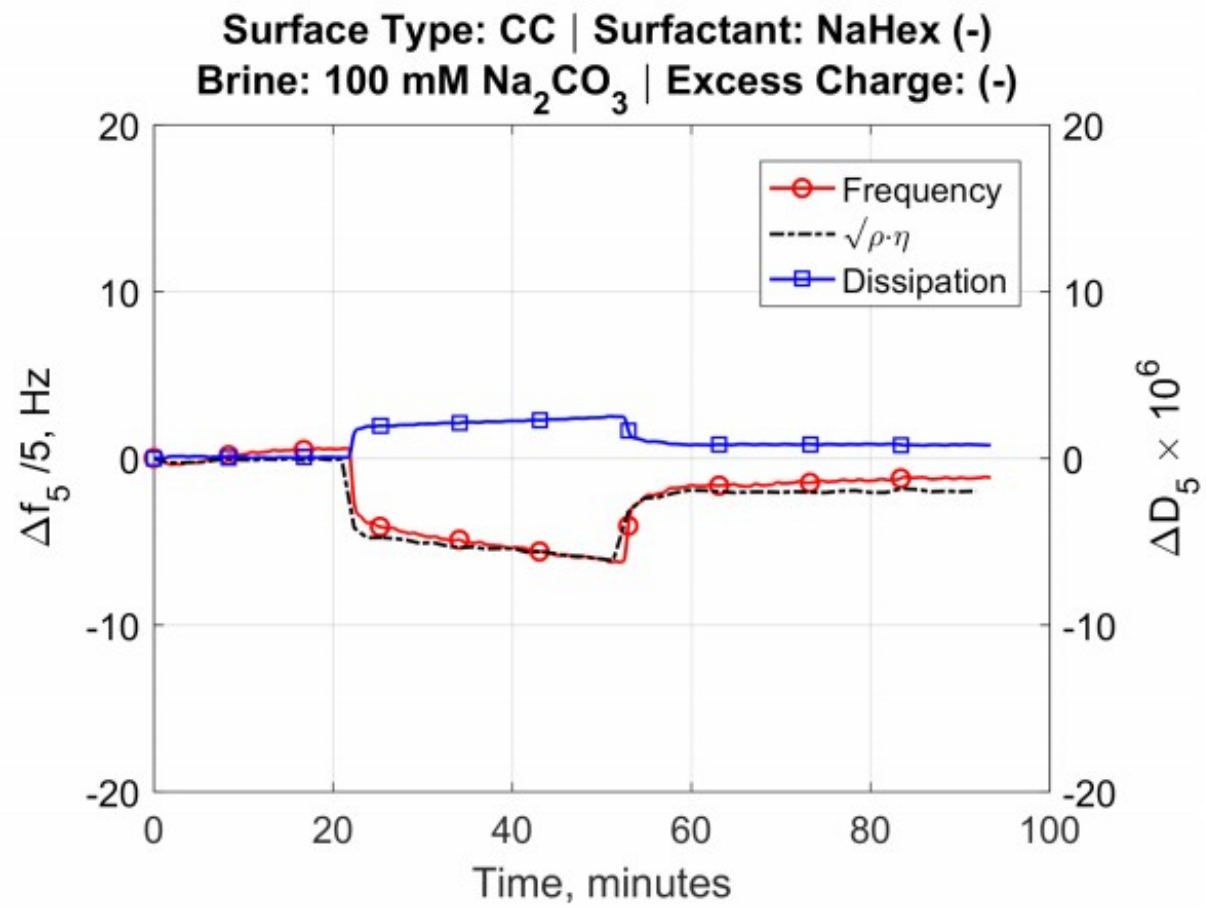

Figure 4 Adsorption of NaHex measured by flow through QCM-D experiment on calcium carbonate. The response at $20 \mathrm{~min}$ is from injection of $50 \mathrm{mM} \mathrm{NaHex}$ in $100 \mathrm{mM} \mathrm{Na} \mathrm{CO}_{3}$, all equilibrated. The PHREEQC calculated equilibrium $\mathrm{pH}$ at atmospheric $\mathrm{CO}_{2}$ is 9.9 , observed 10.1.

Song et al. (2017) reported positive zeta potential for calcium carbonate in $\mathrm{NaCl}$ brine (see first points of each graph in Fig. 3 of the reference). We were not able to reproduce this result (see Fig. 1) and measured negative zeta potential in $100 \mathrm{mM} \mathrm{NaCl}$ brine.

Fig 6 shows the result of adsorption of CTAB/CTAC from $\mathrm{NaCl}$ brine. The experiment sequence is similar to the examples above. The abrupt frequency drop and no change in dissipation correspond to fast adsorption of CTAC onto calcium carbonate. This argues in favor of excess of negative charge on calcium carbonate surface in $\mathrm{NaCl}$ brine.

As above, we studied adsorption of $\mathrm{NaDS}$ on calcium carbonate from $\mathrm{NaCl}$ brine. Fig. 7 shows the result of this experiment. The experiment sequence is similar to the example above. Although notable frequency drop is observed, there is no adsorption as all the change can be explained by densityviscosity difference between baseline and injected solution of NaDS. 


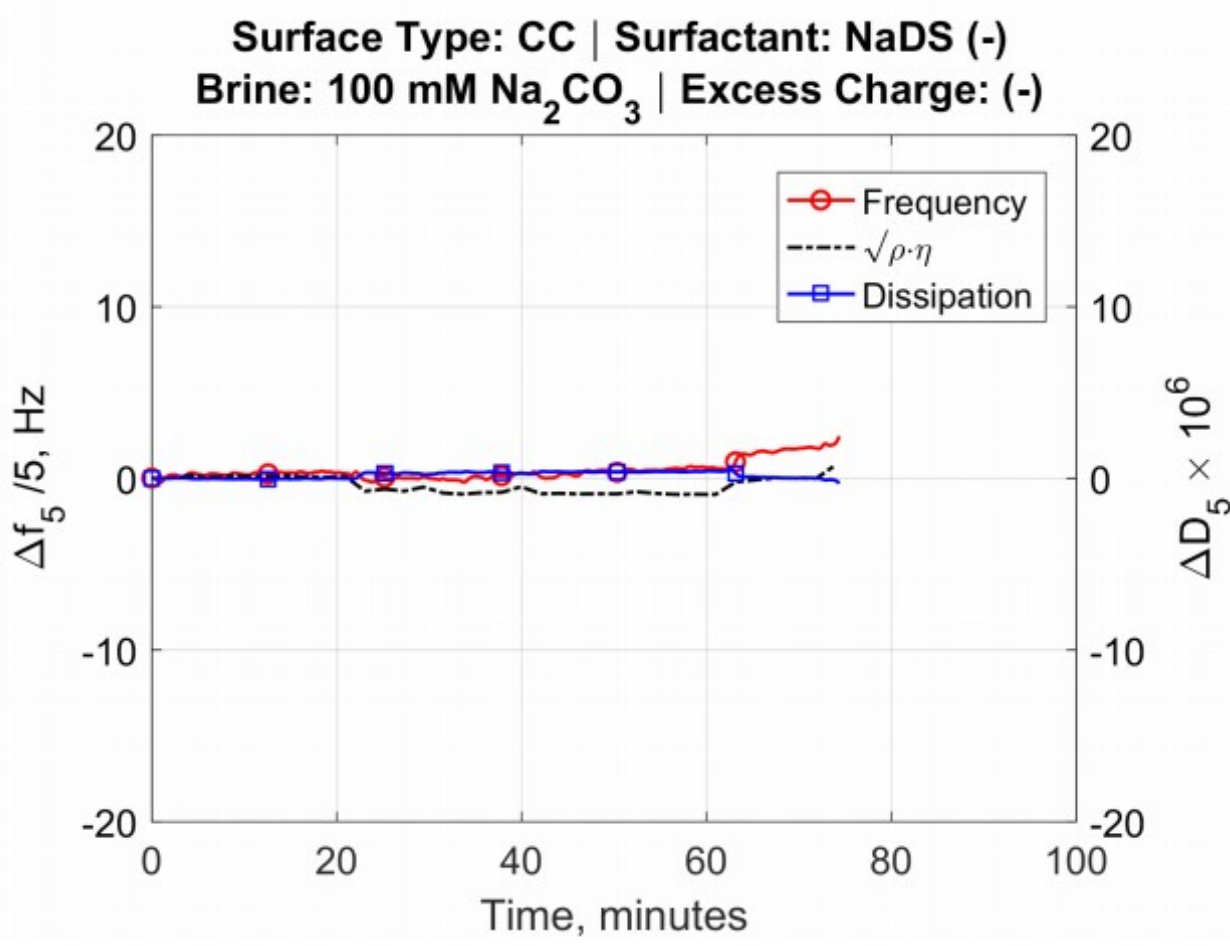

Figure 5 Adsorption of NaDS measured by flow through QCM-D experiment on calcium carbonate. At 20 min a solution containing $5 \mathrm{mM} \mathrm{NaSD}$ in $100 \mathrm{mM}$ equilibrated $\mathrm{Na}_{2} \mathrm{CO}_{3}$ was injected. The PHREEQC calculated equilibrium pH at atmospheric $\mathrm{CO}_{2}$ is 9.9, observed 10.2. 


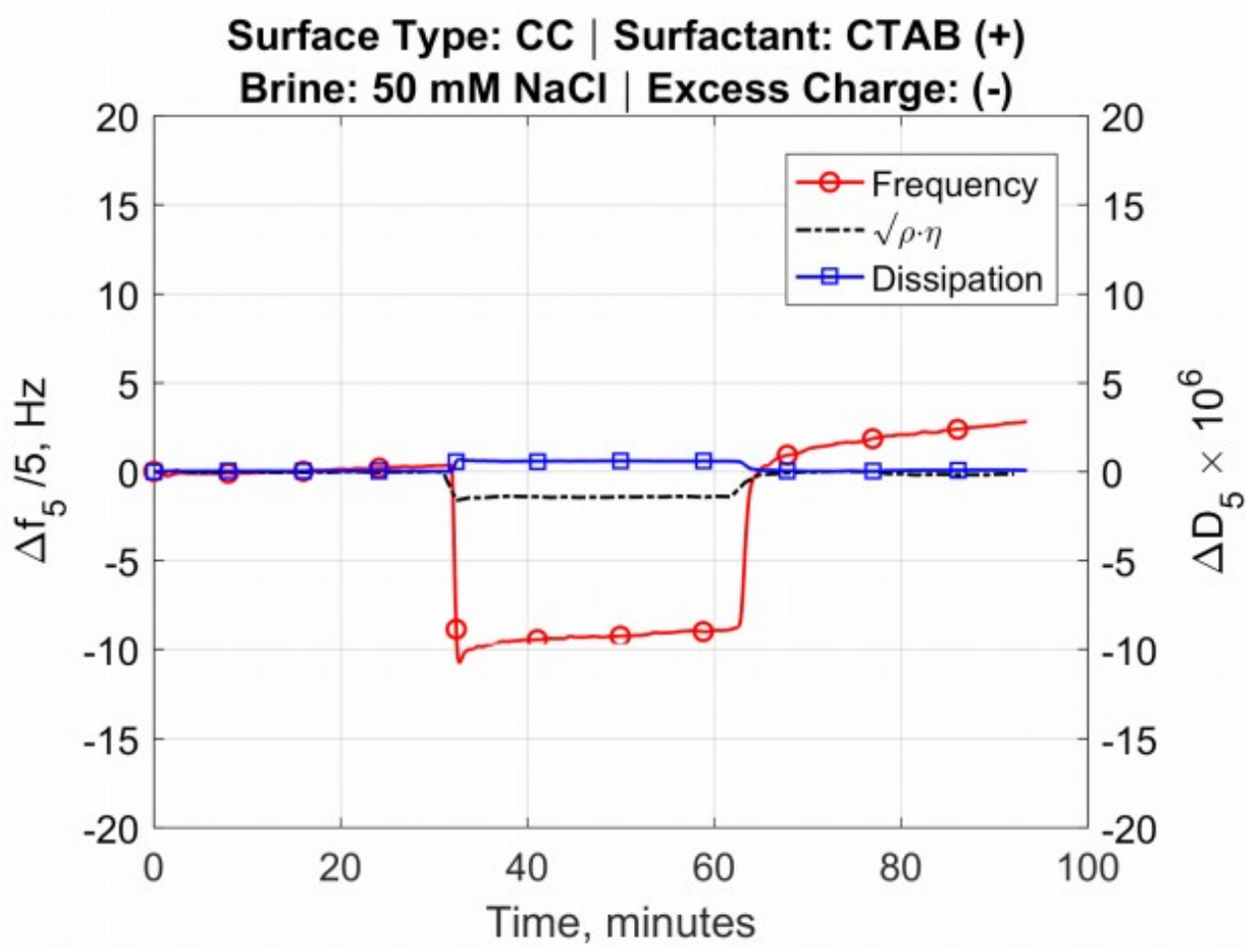

Figure 6 Adsorption of CTAB/CTAC measured by flow through QCM-D experiment on calcium carbonate. The response at $30 \mathrm{~min}$ is from injection of $1 \mathrm{mM} C T A B / C T A C$ in $50 \mathrm{mM}$ of equilibrated $\mathrm{NaCl}$. The PHREEQC calculated equilibrium pH at atmospheric $\mathrm{CO}_{2}$ is 8.4 , observed 8. 


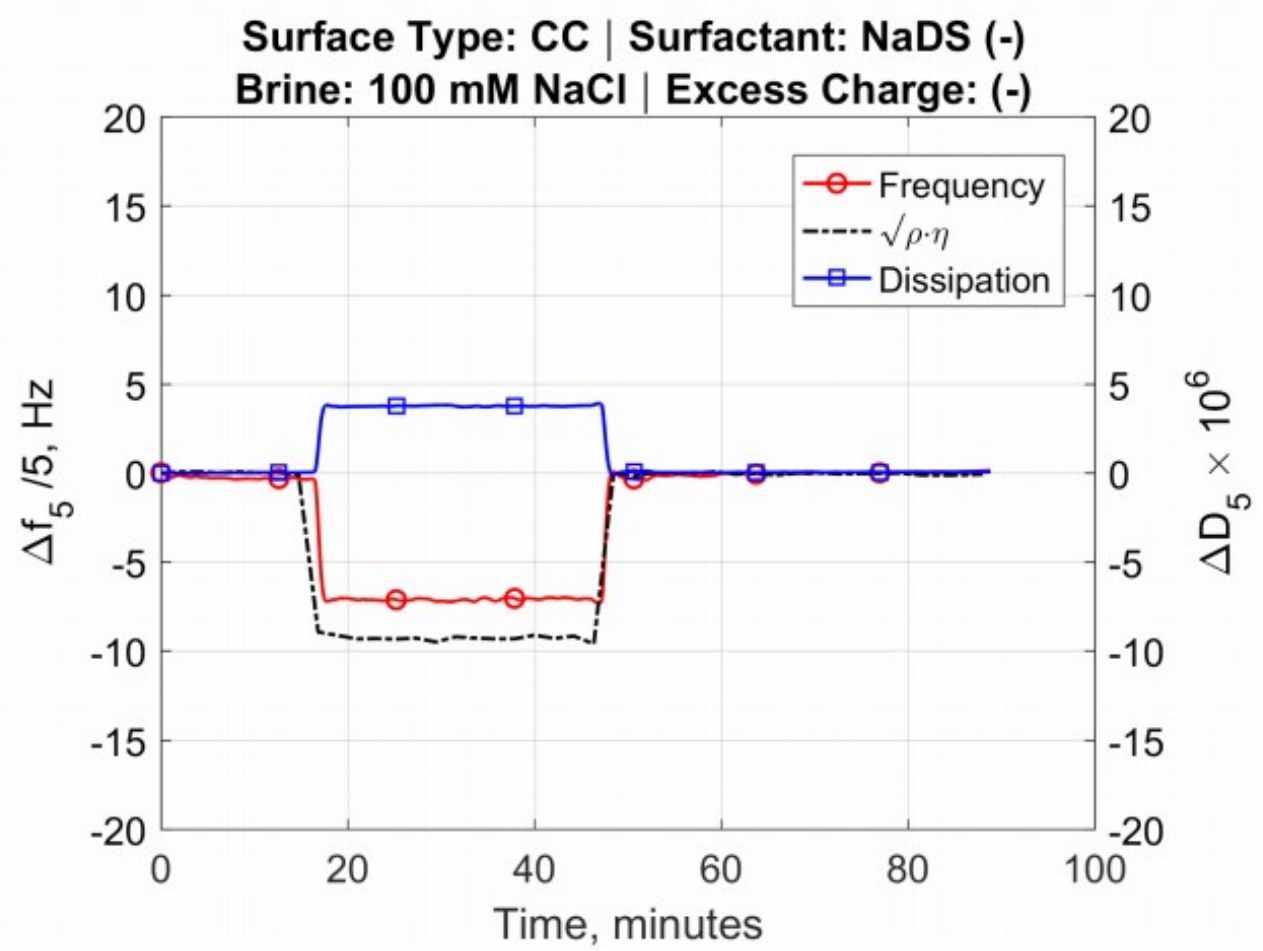

Figure 7 Adsorption of NaDS measured by flow through QCM-D experiment on calcium carbonate. The response at $30 \mathrm{~min}$ is from injection of $0.5 \mathrm{mM} \mathrm{NaDS}$ in $100 \mathrm{mM}$ of equilibrated $\mathrm{NaCl}$. The PHREEQC calculated equilibrium pH at atmospheric $\mathrm{CO}_{2}$ is 8.4 , observed 8.2 .

Overall adsorption behavior of calcium carbonate in sodium chloride suggests that there is negative charge accumulation at its surface, and thus its zeta potential should be negative, which we measure in our experiments. This finding contradicts some published experimental data, which is often used for calibration of surface complexation models. We suggest utmost case when calibrating against zeta potential measurements in $\mathrm{NaCl}$ brines. Adsorption with Excess of Positive Charge at Calcium Carbonate Surface Equilibrated brine with $\mathrm{CaCl}_{2}$ is the only condition in our set of experiments that gives excess of positive charge in the $\beta$-plane of calcium carbonate. However, the measured zeta potential is only $+4 \mathrm{mV}$ (see Fig. 1), which given measurement precision we interpret as neutral or perhaps only slight positive charge excess in the $\beta$-plane.

We studied adsorption of NaHex and NaDS from $\mathrm{CaCl}_{2}$ brine onto calcium carbonate. The presence of calcium sets the limit on concentration of DSions in solution. Surprisingly, we did not find any adsorption of NaHex on the surface. However, NaDS did adsorb even at low concentration. Fig. 8 shows QCM-D response upon injection of $0.5 \mathrm{mM}$ of $\mathrm{NaDS}$ in $100 \mathrm{mM} \mathrm{CaCl}_{2}$ brine. For the first $30 \mathrm{~min}$ a stable baseline is established. At about $30 \mathrm{~min}, 0.5 \mathrm{mM}$ $\mathrm{NaDS}$ solution in $100 \mathrm{mM}$ of equilibrated $\mathrm{CaCl}_{2}$ is injected. The abrupt change of frequency with no change in dissipation indicates adsorption. At about 65 
min, baseline solution is flushed causing desorption. According to Eq. 1, the observed $-2.5 \mathrm{~Hz}$ drop corresponds to $44 \mathrm{ng} / \mathrm{cm}^{2}$ adsorbed, which is less than a monolayer. We note that low concentration of NaDS results in negligible "density-viscosity" effect as well as lower adsorption. This result in not unexpected given close to neutral charge according to zeta potential measurement.

As with the case of negatively charged surface, we also studied adsorption of positively charged surfactants onto calcium carbonate surface in $\mathrm{CaCl}_{2}$ brine. Fig. 9 shows the QCM-D response upon injection of $1 \mathrm{mM} \mathrm{CTAC}$ in equilibrated $100 \mathrm{mM} \mathrm{CaCl}_{2}$ brine. For the first $30 \mathrm{~min}$ a stable baseline is established.

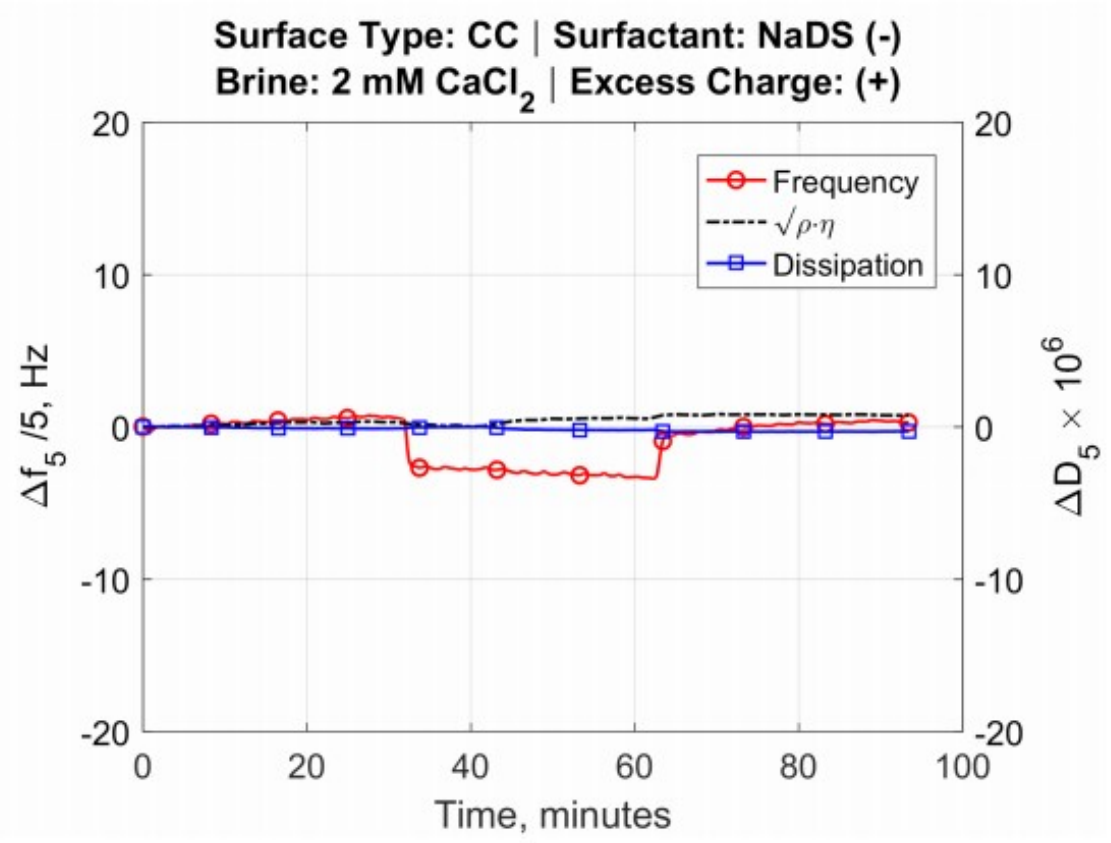

Figure 8 Adsorption of NaDS measured by flow through QCM-D experiment on calcium carbonate. The response at $30 \mathrm{~min}$ is from injection of $0.5 \mathrm{mM} \mathrm{NaSD}$ in $100 \mathrm{mM}$ of equilibrated $\mathrm{CaCl}_{2}$. The PHREEQC calculated equilibrium pH at atmospheric $\mathrm{CO}_{2}$ is 7.4 , observed 7.8 .

At about $30 \mathrm{~min}, 1 \mathrm{mM}$ CTAC solution in $100 \mathrm{mM}$ of equilibrated $\mathrm{CaCl}_{2}$ is injected. The abrupt change of frequency with little change in dissipation indicate adsorption. At about $65 \mathrm{~min}$, baseline solution is flushed causing stepwise desorption. According to Eq. 6 density-viscosity corrected frequency is about $-10 \mathrm{~Hz}$. The adsorbed amount corresponds to 177 $\mathrm{ng} / \mathrm{cm}^{2}$, slightly less than for silica or calcium carbonate with excess of negative charge. Using the same cross-sectional area of $36 \AA^{2}$ we calculate about 1.4 monolayers. 


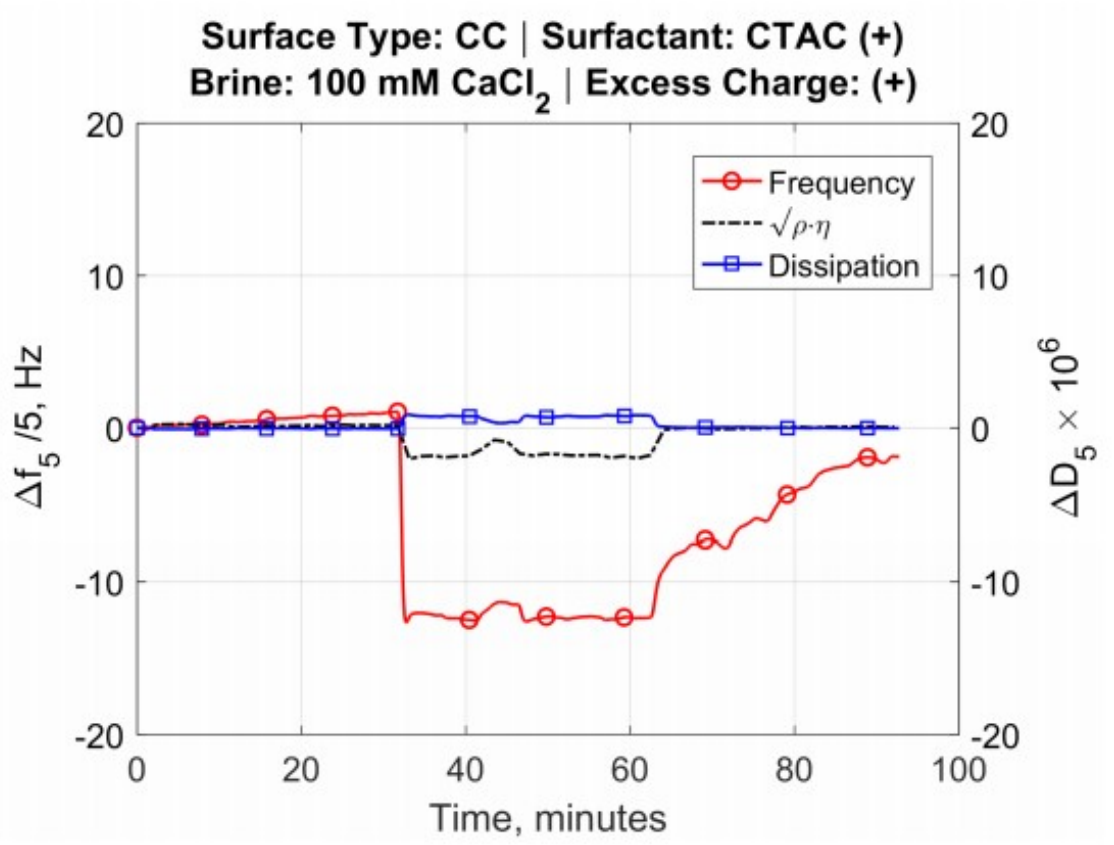

Figure 9 Adsorption of CTAC measured by flow through QCM-D experiment on calcium carbonate. The response at $30 \mathrm{~min}$ is from injection of $1 \mathrm{mM}$ CTAC in $100 \mathrm{mM}$ of equilibrated $\mathrm{CaCl}_{2}$. The PHREEQC calculated equilibrium pH at atmospheric $\mathrm{CO}_{2}$ is 7.4 , observed 7.4 .

This result looks unexpected. Additionally, CTAC and NaDS have about the same chain length, which implies no preferential adsorption due to weak hydrophobic interactions. However, one should remember that calcium carbonate surface is neutral, and all the species compete for interactions in the $\beta$-plane. In this regards CTAB/CTAC ions are equal to calcium ions or any other ions in the solution. So, strong specific interaction of CTAB/CTAC with the surface lets it out compete calcium ions and adsorb preferentially. In order to exclude calcium carbonate coating damage or permeation that could have caused such result, we confirmed preliminary its integrity in our AFM experiments (see Appendix B).

\section{Conclusions}

Our results suggest that some functional groups (e.g., positively charged amines) from asphaltenes dissolved in crude oil can interact with calcium carbonate surface in almost any brine. This finding is not limited to a particular functional group. Therefore, any functional group present at crude oil-brine interface could interact with calcium carbonate surface regardless of accumulated charge, provided it has strong specific affinity to the surface. The findings in this paper make the LSW process appear to depend on a specific combination of crude oil, formation rock and brine properties. It is a confluence of several necessary conditions (a product of several logical AND statements) that may make a successful LSW project, if all of these conditions are satisfied by the specific crude-brine-rock interactions. 
In Table 2, we summarize adsorption of three charged surfactants. These results were obtained by QCMD technique. Bulk adsorption experiments were not successful, likely due to low specific surface areas of the calcium carbonate powders.

CTAC (quaternary ammonium surfactant, positively charged) has high affinity to calcium carbonate surface and adsorbs in comparable amounts on calcium carbonate surface in both excess of negative charge or neutral state. Compared to sodium dodecyl sulfate (NaDS), CTAC appears to be more potent in competing with other ions, like sodium, calcium, or bicarbonate in the $\beta$-plane. Any other functional group with strong specific interaction would have behaved similarly. NaDS and sodium hexanoate (NaHex) show weak and nonexistent adsorption respectively. This rather surprising finding can be explained by poor choice of model compound in case of the hexanoate. Compared to CTAC or NaDS, NaHex has orders of magnitude higher water solubility, which seems to makes adsorption less favorable. Unfortunately, we cannot draw any conclusions about carboxylic group.

From the fundamental point of view, elucidation of cation and counter-ion effects in this process may be worth pursuing. One anticipates that the low hydration energy cations such as rubidium, cesium, or barium should disfavor CTAC adsorption and vice versa.

Table 2 A summary of QCM-D adsorption results for calcium carbonate and three surfactants used in this work: CTAC (positively charged), NaDS (negatively charged), and NaHex (negatively charged). The three brines used: $\mathrm{Na}_{2} \mathrm{CO}_{3} 100 \mathrm{mM}$ (excess of negative ions), $\mathrm{NaCl} 50-100 \mathrm{mM}$ (excess of negative ions), $\mathrm{CaCl}_{2} 100 \mathrm{mM}$ (excess of positive ions).

\begin{tabular}{|c|c|c|c|c|}
\hline Surface charge & Brine & CTAC $(+)$ & $\operatorname{NaDS}(-)$ & $\mathrm{NaHex}(-)$ \\
\hline Negative & $\mathrm{Na}_{2} \mathrm{CO}_{3}$ & adsorbs (Fig. 3) & doesn't adsorb (Fig. 5) & doesn’t adsorb (Fig. 4) \\
\hline Negative & $\mathrm{NaCl}$ & adsorbs (Fig. 6) & doesn't adsorb (Fig. 7) & N/A \\
\hline Positive & $\mathrm{CaCl}_{2}$ & adsorbs (Fig. 9) & adsorbs (Fig. 8) & doesn't adsorb \\
\hline
\end{tabular}

Acknowledgments

This project was funded by prof. Patzek's baseline research grant (SK, MPY). SFH would like to thank Saudi Aramco/EXPEC Advanced Research Center for sponsoring his PhD studies at the King Abdullah University of Science and Technology (KAUST).

Appendix A. Bulk Adsorption on Calcium Carbonate

A fixed amount of silica micropowder $\left(\sim 5 \mathrm{~m}^{2} / \mathrm{g}\right)$ and calcite nanopowder ( $2.5 \mathrm{~m}^{2} / \mathrm{g}$ ) were added to the surfactant solution (15 g in $100 \mathrm{ml}$ ). Samples were stirred vigorously for 10 minutes using a laboratory shaker and ultrasonic bath then centrifuged before filtering the powder. Table Al shows total organic carbon analysis of the filtered supernatant after adsorption of CTAC and NaHex. 
TOC analysis of CTAC adsorption on silica shows organic content change from 192 to $4 \mathrm{ppm}$ for $\mathrm{NaCl}$. This clearly indicates adsorption. Similar result was obtain for $\mathrm{CaCl}_{2}$ brine. Contrary to silica, calcite nano powder did not result in notable changes in organic content. We associate such result with high agglomeration tendency of the nano particles. As expected for silica there was not adsorption of NaHex (Hu et al., 2019). Calcite nanopowder also did not yield any adsorption. This result cross-confirms QCM-D results for calcium carbonate.

Table A1 Bulk adsorption TOC analysis for experiments with $1 \mathrm{mM}$ CTAC and $50 \mathrm{mM}$ NaHex

\begin{tabular}{|c|c|c|c|}
\hline Solution $^{a}$ & Baseline, ${ }^{b}$ ppm & Silica powder, ${ }^{c} \mathrm{ppm}$ & Calcite powder, ${ }^{c} \mathrm{ppm}$ \\
\hline & & \multicolumn{2}{|l|}{ CTAC } \\
\hline $\mathrm{NaCl} 300 \mathrm{mM}$ & 192 & 4 & 198 \\
\hline $\mathrm{CaCl}_{2} 100 \mathrm{mM}$ & 199 & 6 & 203 \\
\hline \multicolumn{4}{|c|}{ NaHex } \\
\hline $\mathrm{CaCl}_{2} 100 \mathrm{mM}$ & 3633 & 3763 & 3673 \\
\hline $\mathrm{Na}_{2} \mathrm{CO}_{3} 100 \mathrm{mM}$ & 3766 & 3737 & 3712 \\
\hline
\end{tabular}

${ }^{a}$ All solutions were equilibrated at atmospheric $\mathrm{CO}_{2}$ partial pressure

${ }^{b}$ Only surfactant is added to equilibrated solution

${ }^{c}$ Amount is $15 \mathrm{~g} / 100 \mathrm{ml}$ of solution

Appendix B. QCM-D Validation, and Sensor Characterization Adsorption of CTAB on Silica

Cetyltrimethylammonium bromide (CTAB) is a quaternary ammonium surfactant with positively charged hydrophilic head. Its adsorption onto negatively charged silica surface has been extensively studied (Theodoly et al., 2005; Velegol et al., 2000; Atkin et al., 2000; ller and K, 1979; Bijsterbosch, 1974, and references therein).

It was found that typical uptake values for CTAB on silica in the presence of electrolyte fall within the range of 1 to $2.1 \mathrm{mg} / \mathrm{m}^{2}$ (Atkin et al., 2000; Velegol et al., 2000, and refrences therein). CTAB typically forms bilayers or partial bilayers at close to critical micelle concentration (CMC) (Velegol et al., 2000).

Fig. B1 shows QCM-D response to injection of $1 \mathrm{mM}$ of CTAB in $150 \mathrm{mM} \mathrm{NaCl}$ electrolyte at $\mathrm{pH}$ of 8.2 . For the first $30 \mathrm{~min}$ a stable baseline was established. At 30 min mark, $1 \mathrm{mM}$ CTAB solution in $150 \mathrm{mM}$ of $\mathrm{NaCl}$ was injected. Abrupt change in frequency suggests strong and fast adsorption of CTAB to silica surface. At about 60 min mark, baseline solution was flushed causing desorption. According to eq. 1 the adsorbed amount $(\Delta f=14 \mathrm{~Hz}$ corresponds to $248 \mathrm{ng} / \mathrm{cm}^{2}\left(2.48 \mathrm{mg} / \mathrm{m}^{2}\right)$ ). For bilayer adsorption this yields about $36 \AA^{2}$ - a good match with published data (Velegol et al., 2000, Fig. 2). The desorption process is two step confirming the bilayer adsorption.

These results let us conclude that QCM-D method and the above theory are reliable enough and compare to bulk adsorption methods in accuracy. The 
method allowed us to bypass surface area limitation and study adsorption on calcium carbonate.

Calcium Carbonate Sensors Characterization

We experienced issues with chemical and mechanical stability, while working with calcium carbonate coated quartz resonators in aqueous media. As reported by the QCM-D supplier the thickness of calcium carbonate coating is about $100 \mathrm{~nm}$. Given high reactivity and fast kinetics of calcium carbonate, chemical equilibration of any brine that goes in contact with the coating is of utmost importance.

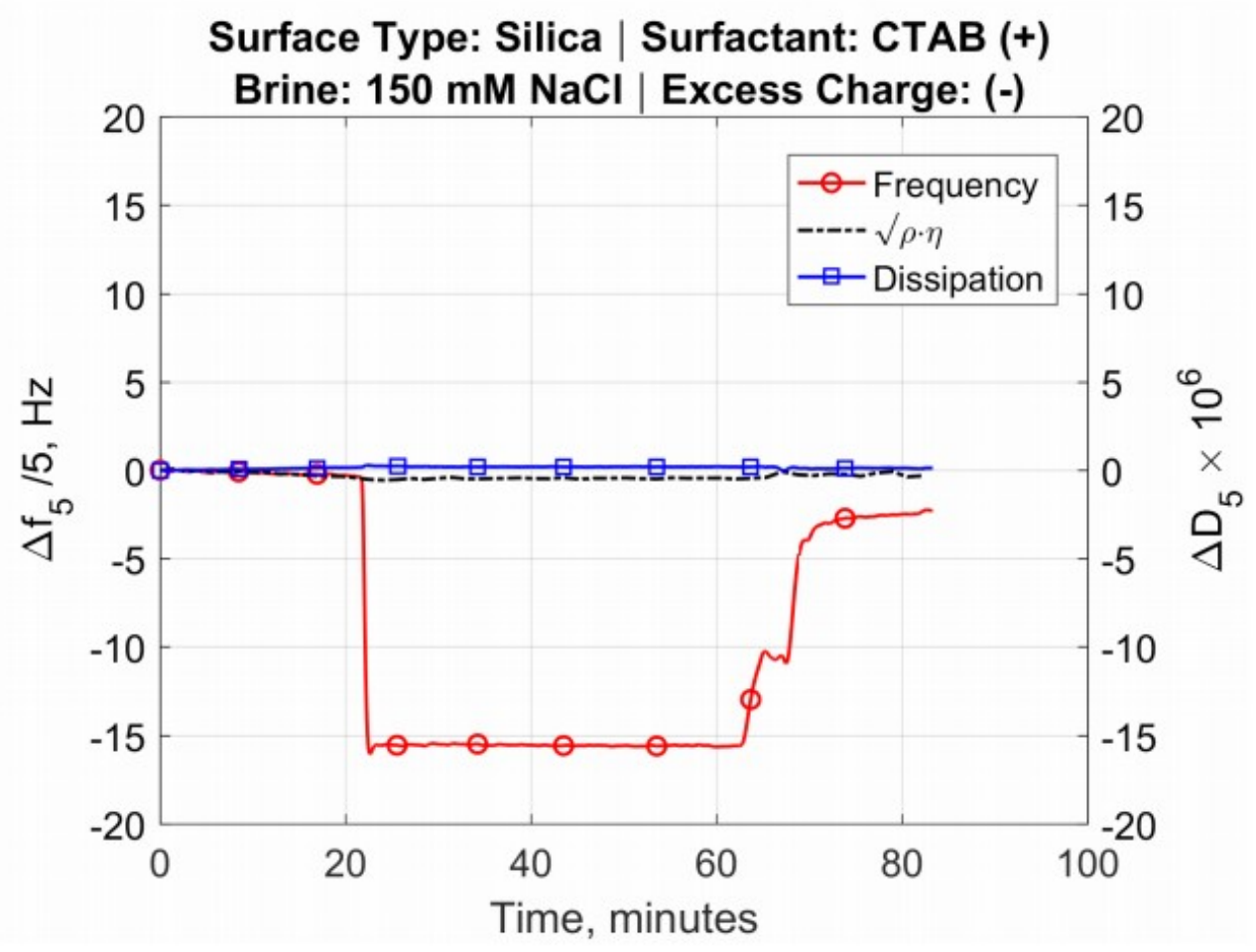

Figure B1 Adsorption of CTAC on silica measured by flow through QCM-D experiment on silica. The response at $20 \mathrm{~min}$ is from injection of $1 \mathrm{mM} \mathrm{CTAB}$ in $150 \mathrm{mM}$ of $\mathrm{NaCl}$.

Additionally, because of underlying silica coating, the permeability if calcium carbonate coating is of great importance. A permeable coating would produce doubtful adsorption results by interference with silica adsorption.

Supported coating permeability study is a challenging task. We attempted to characterize the coating integrity before and after experiments using AFM method.

AFM was used to evaluate roughness of calcium carbonate coating through the z-sensor channel (topography channel). Images are obtained using Bruker Dimension Icon Model (Bruker Corporation, Massachusetts, CA, USA) under air tapping mood with a RTESPA tip (MPP-11120, $\mathrm{k}=20-80 \mathrm{~N} / \mathrm{m}$ ). The scan rate is $0.996 \mathrm{~Hz}$ with a resolution of 512 samples per line. Sampling points are selected around the center of sensor to be scanned at multiple 
levels $\left(10 \times 10,1 \times 1\right.$, and $\left.0.25 \times 0.25 \mu \mathrm{m}^{2}\right)$; only $\left(1 \times 1 \mu \mathrm{m}^{2}\right.$ is shown in the paper). Gwyddion software is used to process, visualize and analyze all data.

Fig. B2a features one of $1 \times 1 \mu \mathrm{m}^{2}$ scans of pristine calcium carbonate coating topography with maximum roughness not higher than $5.6 \mathrm{~nm}$ and $\mathrm{Rq}=0.7$ $\mathrm{nm}$. Fig. B2b shows a similar region of the coating that was one time used for adsorption study. The maximum roughness is not higher than $5.6 \mathrm{~nm}$ with $\mathrm{Rq}$ $=0.67 \mathrm{~nm}$. Given reported coating thickness we can tentatively conclude that coating retained its integrity. Another possible sign of coating low permeability is fast adsorption of CTAB. A permeable coating establishes diffusion limited control on adsorption rate, which would be evident from QCM-D signal. Yet such analysis is not enough to completely exclude interaction of injected brines with the underlying silica surface. A more thorough study is on the way.

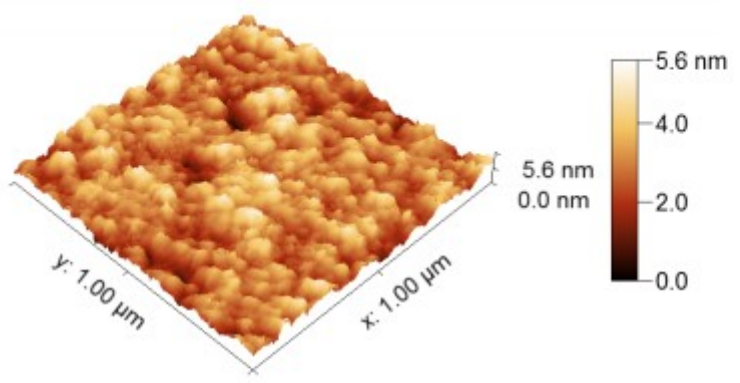

(a) New freshly cleaned calcium carbonate sensor

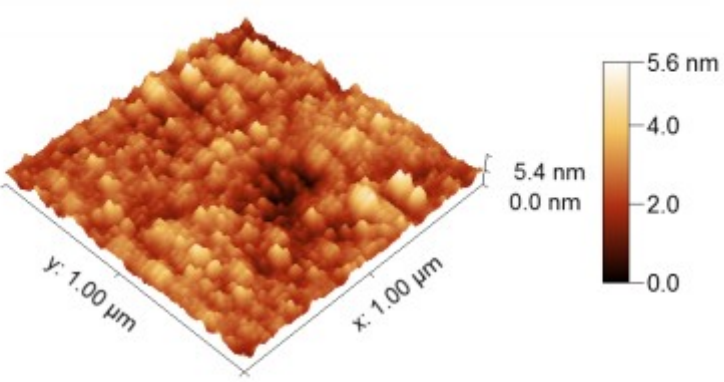

(b) Used calcium carbonate sensor after rinsing

Figure B2 Exemplary AFM topography scans of $1 \times 1 \mu \mathrm{m}^{2}$ area of new (a) and used (b) calcium carbonate coatings on $Q C M-D$ resonators. 


\section{Appendix C. PHREEQC Input Files}

\section{Charged Form Percentage}

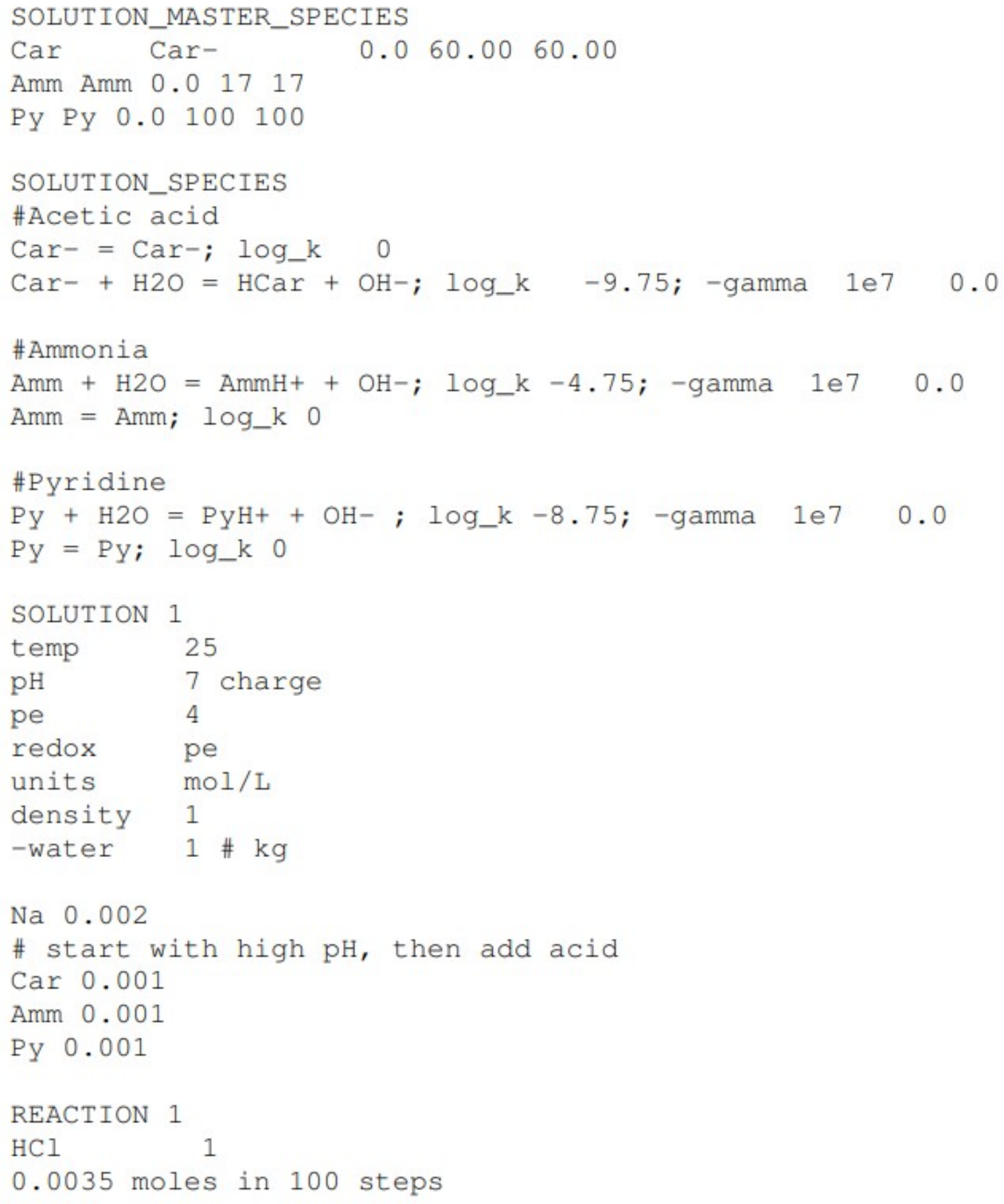




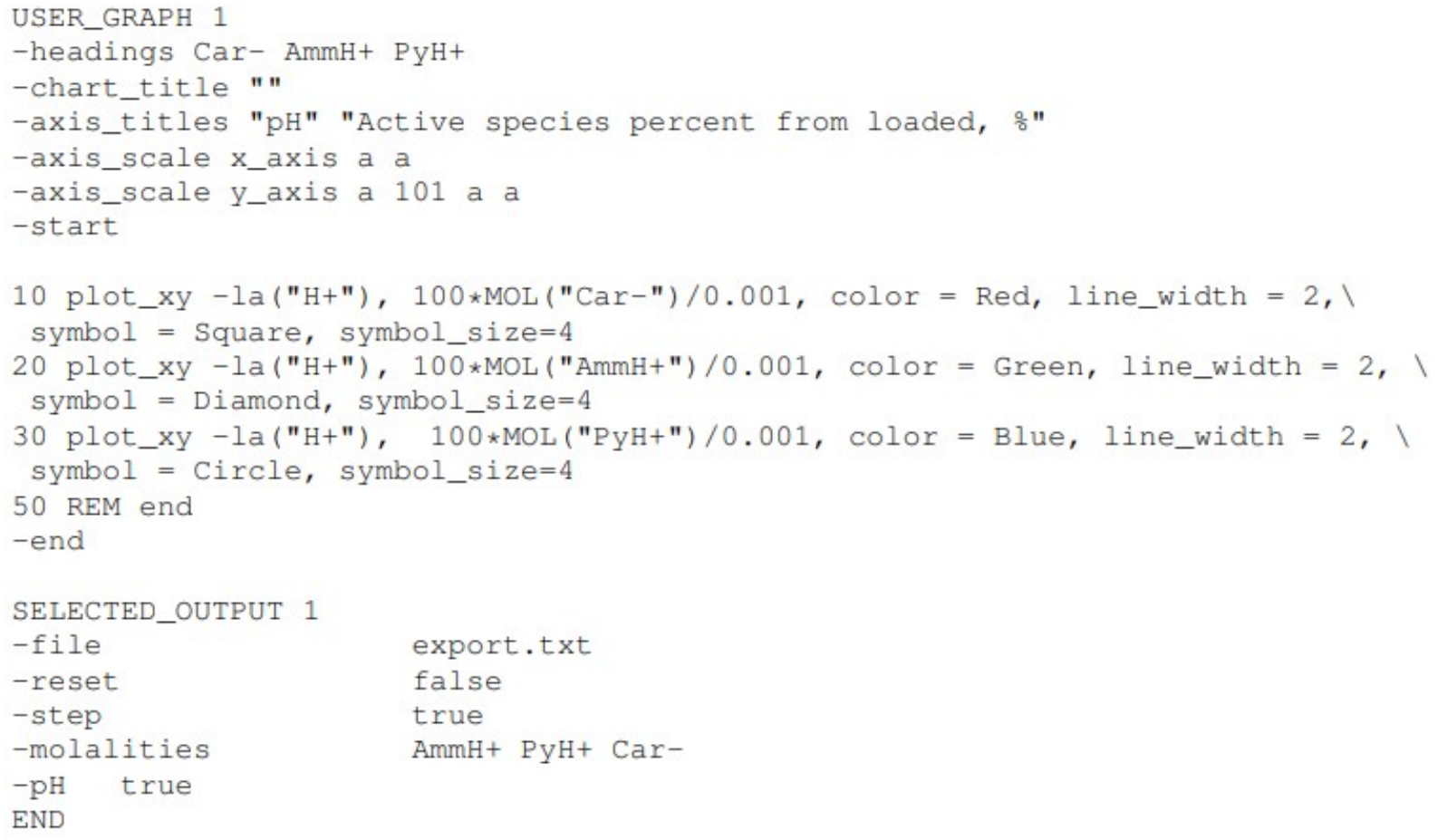

END

\section{Calcite Equilibrium $\mathrm{pH}$}

\begin{tabular}{ll}
\multicolumn{2}{l}{ Calcite Equilibrium $\boldsymbol{p H}$} \\
SOLUTION & 1 \\
temp & 21 \\
pH & 7 charge \\
pe & 4 \\
redox & pe \\
units & mol/L \\
density & 1 \\
-water & 1 \# kg \\
& \\
EQUILIBRIUM_PHASES 1 \\
Calcite & 0 10 \\
CO2(g) & -3.5 10 \\
END & \\
solutION & 1 \\
temp & 21 \\
pH & 7 charge \\
pe & 4 \\
redox & pe \\
units & mol/L \\
density & 1 \\
-water & 1 \# kg \\
Ca 0.1 & \\
Cl 0.2 & \\
EQUILIBRIUM_PHASES 1
\end{tabular}




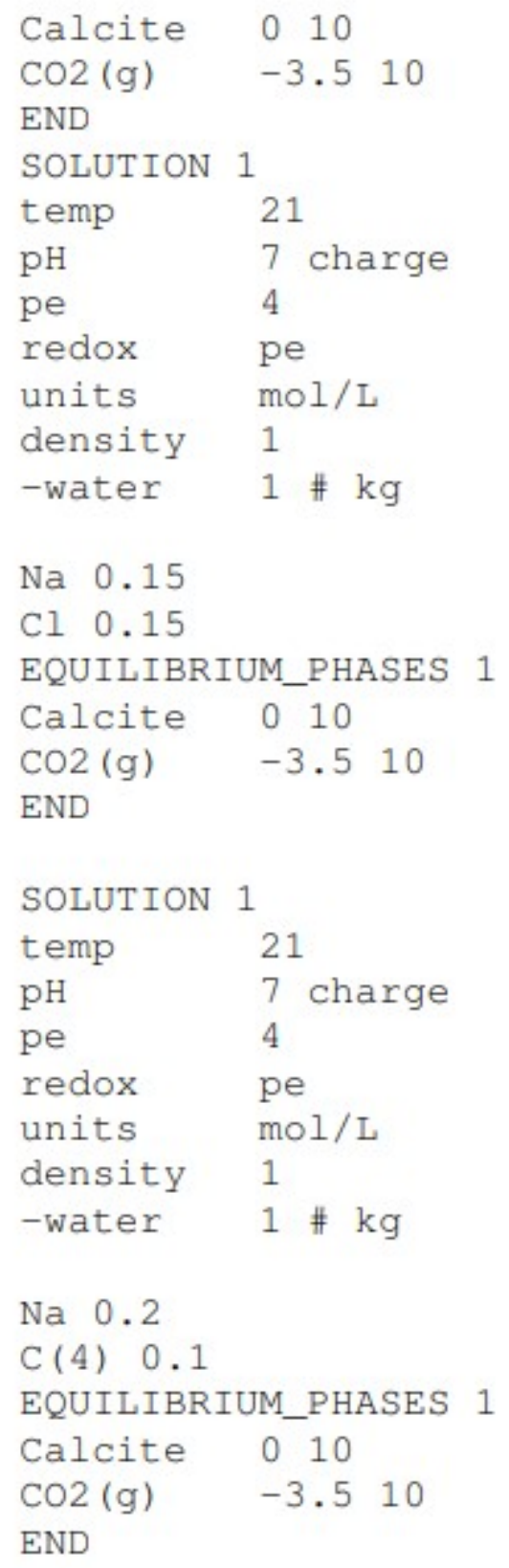
with high chloride content, it is possible to say that such experiments would be indistinguishable from those run with CTAC. Hence, we use these chemicals interchangeably throughout the manuscript implying it is the CTA ${ }^{+}$ ion that participates in interaction.

References 
Atkin, R., Craig, V.S.J. and Biggs, S. [2000] Adsorption Kinetics and Structural Arrangements of Cationic Surfactants on Silica Surfaces. Langmuir, 16(24), 9374-9380.

Bai, G. and Xu, Y. [2014] Giant fields retain dominance in reserves growth. Oil and Gas Journal, 122(2), 44-51.

Bijsterbosch, B. [1974] Characterization of Silica Surfaces by Adsorption From Solution. Investigations Into the Mechanism of Adsorption of Cationic Surfactants. Journal of Colloid and Interface Science, 47(1), 186-198.

Brady, P.V. and Thyne, G. [2016] Functional Wettability in Carbonate Reservoirs. Energy \& Fuels, 30(11), 9217-9225.

Eftekhari, A.A., Thomsen, K., Stenby, E.H. and Nick, H.M. [2017] Thermodynamic Analysis of Chalk- Brine-Oil Interactions. Energy \& Fuels, 31(11), 11773-11782.

Heberling, F., Trainor, T.P., Lützenkirchen, J., Eng, P., Denecke, M.A. and Bosbach, D. [2011] Structure and Reactivity of the Calcite-Water Interface. Journal of Colloid and Interface Science, 354(2), 843- 857.

Hiorth, A., Cathles, L.M. and Madland, M.V. [2010] The Impact of Pore Water Chemistry on Carbonate Surface Charge and Oil Wettability. Transport in Porous Media, 85(1), 1-21.

Hu, X., Yutkin, M.P., Hassan, S., Wu, J., Prausnitz, J.M. and Radke, C.J. [2019] Calcium Ion Bridging of Aqueous Carboxylates Onto Silica: Implications for Low-Salinity Waterflooding. Energy \& Fuels, 33(1), 127-134.

Hunter, R.J. [1981] Zeta Potential in Colloid Science. Elsevier.

Iler, R. and K, I.R. [1979] The Chemistry of Silica: Solubility, Polymerization, Colloid and Surface Properties and Biochemistry of Silica. A WileyInterscience publication. Wiley.

Kanazawa, K.K. and Gordon, J.G. [1985] Frequency of a quartz microbalance in contact with liquid. Analytical Chemistry, 57(8), 1770-1771.

Lager, A., Webb, K. and Seccombe, J. [2011] In: Low Salinity Waterflood, Endicott, Alaska: Geochemical Study \& Field Evidence of Multicomponent Ion Exchange.

Lager, A., Webb, K.J., Black, C.J.J., Singleton, M. and Sorbie, K.S. [2006] Low Salinity Oil Recovery - An Experimental Investigation. Society of Core Analysts Annual Conference.

Morrow, N. and Buckley, J. [2011] Improved Oil Recovery by Low-Salinity Waterflooding. Journal of Petroleum Technology, 63(5), 106-112.

Necas, D. and Klapetek, P. [2012] Gwyddion: An Open-Source Software for SPM Data Analysis. Central European Journal of Physics, 10, 181-188. 
Parkhurst, D.L. and Appelo, C.A.J. [2013] Description of Input and Examples for PHREEQC Version 3-A Computer Program for Speciation, Batch-Reaction, One-Dimensional Transport, and Inverse Geochemical Calculations.

Rodahl, M. and Kasemo, B. [1995] On the Measurement of Thin Liquid Overlayers With the QuartzCrystal Microbalance. In: Proceedings of the International Solid-State Sensors and Actuators Conference - TRANSDUCERS '95, 2. IEEE, 743-746.

Sauerbrey, G. [1959] Verwendung von Schwingquarzen zur Wägung dünner Schichten und zur Mikrowägung. Zeitschrift für Physik, 155(2), 206-222.

Song, J., Zeng, Y., Wang, L., Duan, X., Puerto, M., Chapman, W.G., Biswal, S.L. and Hirasaki, G.J. [2017] Surface Complexation Modeling of Calcite Zeta Potential Measurements in Brines With Mixed Potential Determining lons $(\mathrm{Ca} 2+, \mathrm{CO} 2-3, \mathrm{Mg} 2+, \mathrm{SO} 2-4)$ for Characterizing Carbonate Wettability. Journal of Colloid and Interface Science, 506, 169-179.

Srisuriyachai, F. and Meekangwal, S. [2017] Evidence of Multi-Component Ion Exchange in Dolomite Formation During Low Salinity Waterflooding. IOP Conference Series: Earth and Environmental Science, 95, 032037.

Tang, G. and Morrow, N. [1997] Salinity, Temperature, Oil Composition, and Oil Recovery by Waterflooding. SPE Reservoir Engineering, 12(November), 269-276.

Theodoly, O., Cascão-Pereira, L., Bergeron, V. and Radke, C.J. [2005] A Combined Streaming-Potential Optical Reflectometer for Studying Adsorption at the Water/Solid Surface. Langmuir, 21(22), 10127- 10139.

Velegol, S.B., Fleming, B.D., Biggs, S., Wanless, E.J. and Tilton, R.D. [2000] Counterion Effects on Hexadecyltrimethylammonium Surfactant Adsorption and Self-Assembly on Silica. Langmuir, 16(6), 2548-2556.

Voinova, M.V., Rodahl, M., Jonson, M. and Kasemo, B. [1999] Viscoelastic Acoustic Response of Layered Polymer Films at Fluid-Solid Interfaces: Continuum Mechanics Approach. Physica Scripta, 59(5), 391-396.

Yousef, A.A., Al-Saleh, S.H., Al-Kaabi, A., Al-Jawfi, M.S. et al. [2011] Laboratory investigation of the impact of injection-water salinity and ionic content on oil recovery from carbonate reservoirs. SPE Reservoir Evaluation \& Engineering, 14(05), 578-593.

Yutkin, M.P., Lee, J.Y., Mishra, H., Radke, C.J. and Patzek, T.W. [2016] Bulk and Surface Aqueous Speciation of Calcite: Implications for Low-Salinity Waterflooding of Carbonate Reservoirs. In: SPE Kingdom of Saudi Arabia Annual Technical Symposium and Exhibition. Society of Petroleum Engineers. 